Copyright (C) 2015 by Academic Publishing House Researcher

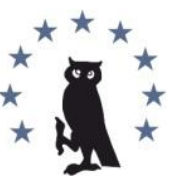

Published in the Russian Federation

European Researcher

Has been issued since 2010.

ISSN 2219-8229

E-ISSN 2224-0136

Vol. 90, Is. 1, pp. 55-60, 2015

DOI: 10.13187/er.2015.90.55

www.erjournal.ru

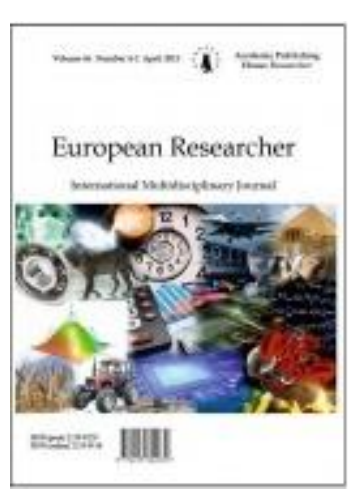

UDC 81'23:811.111

\title{
The Types of Personal Networks in the Texts Containing Descriptions of Dematerialization of a Subject
}

\author{
${ }^{1}$ Ella V. Nesterik \\ ${ }^{2}$ Natalya S. Rozhayeva
}

\begin{abstract}
${ }^{1}$ Karaganda State University named after E.A.Buketov, Kazakhstan
Mukanov street 1a, Karaganda city, Karagandinskaya Oblast, 100026

$\mathrm{PhD}$ (Philology), Assistant Professor

E-mail: ella_nesterik@mail.ru

${ }^{2}$ Karaganda State University named after E.A.Buketov, Kazakhstan

Mukanov street 1a, Karaganda city, Karagandinskaya Oblast, 100026

E-mail:minik25@mail.ru
\end{abstract}

\begin{abstract}
The article examines the types of personal networks found in the descriptions of dematerialization of a subject and reveals the role of the linguistic means expressing the category of personality in the linguistic embodiment of this phenomenon. The research is conducted at the junction of several disciplines, among which text linguistics takes the leading place. The authors come to the conclusion that dematerialization is formed in a literary text by explicit means of expression of personality - predicates of a certain type and pronominal personal network.

Keywords: Dematerialization; category of personality; personal network; explicit means of expression of personality; explicit personal network; linguistic embodiment of dematerialization.

\section{Введение}

На протяжении всей своей истории человечество проявляло устойчивый интерес ко многим необъяснимым явлениям и загадкам, начиная с природных явлений и заканчивая исчезновением людей и предметов. Прошли столетия, а некоторые из этих феноменов все еще не получили объяснения. Так, исчезновение людей занимает 4 место в списке самых невероятных явлений. На этот счет выдвигаются разные версии, начиная с криминальной и заканчивая сверхъестественной, где последняя занимает особое место. Способность человека по своей воле спонтанно превращаться из объекта материального мира в луч и исчезать именуется сегодня дематериализацией.

Существуют различные интерпретации этого понятия, и все они непосредственно связаны с парапсихологией, рассматривающей дематериализацию как материальноэнергетическое пси-явление.

Наиболее полное и точное определение было найдено в мультиязычной Интернетэнциклопедии, где дематериализация трактуется как «...мифологическое представление о способности человека по своей воле мгновенно (или в течение короткого отрезка времени) превращаться из объекта материального мира в «столп света» (либо превращаться
\end{abstract}


частично, оставляя какие-либо остатки тела, например, волосы или ногти) либо исчезать вовсе как объект материального мира без какого-либо внешнего воздействия. Также к дематериализации относят одновременное появление человека или объекта в двух и более местах...» [1] и исчезновение материальных тел при реализации некоторых псифеноменов [2].

Процесс дематериализации иногда связывают с телепортацией, способностью объекта перемещаться из одного места в другое за очень короткий промежуток времени (практически мгновенно), не существуя в промежуточных точках между ними, при помощи технологических методов или паранормальных явлений [3]. Дематериализация прослеживается в технологическом методе телепортации, когда происходит процесс передачи информации об объекте из одной точки в другую, при этом объект в первой точке в ходе передачи информации исчезает, а материал тела или вещества используется как носитель информации, из которого потом и воссоздаётся тело или вещество, идентичное прежнему [4]. Однако научного подтверждения реального существования телепортации (кроме квантовой телепортации - передачи энергии или материи на расстояния) пока не найдено [5].

В уфологии дематериализация представляет собой постепенное или мгновенное исчезновение НЛО на глазах у очевидцев)» [6].

Явление дематериализации вызывает интерес не только у парапсихологов, эзотериков и др., но и писателей, работающих в жанре мистики. Последние используют данный феномен для создания мистического образа или ситуации в своих произведениях.

Изучение определений дематериализации, представленных в словарях и прочих источниках, позволило обозначить рамки поиска примеров этого явления в художественном тексте.

Изучение дематериализации с позиций лингвистики текста позволило выявить набор языковых средств, участвующих в ее воплощении.

В первую очередь, изменения наблюдаются в текстовой структуре, для описания которой с точки зрения категории лица некоторые исследователи вводят понятие «персональной сетки» (например, Л.А.Ноздрина [7, 33]).

Персональность, согласно Е.Ю.Стратийчук, является ведущей текстообразующей категорией и присуща текстам, созданным на разных языках [8]. Обусловлено это тем, что автор текста организует повествование на основе своей точки зрения. Возможно, именно поэтому категория персональности рассматривается в трудах многих лингвистов как категория «образа автора».

Образ автора - это организующая сила произведения, объединяющая в единое целое его отдельные части, пронизывающая его единым мировоззрением. Образ автора представляет собой определённое отвлечение от биографической реальности, всегда несколько идеализированное [9].

Согласно исследованию Е.Ю.Стратийчук, в качестве составного понятия текстообразующей категории персональности может выступать модальность. Модальность понятийная категория со значением отношения говорящего к содержанию высказывания и отношения содержания высказывания к действительности (отношения сообщаемого к его реальному осуществлению). Модальность бывает субъективной и объективной. Первая - это отношение говорящего к тому, что он выражает, что позволяет сформировать текстовую категорию персональности, т.е. формирует текст. Объективная же модальность - это время, лицо и пространство [8].

Текстообразующая категория персональности может также рассматриваться с точки зрения лексико-семантических и грамматических средств выражения. Анализ, проведенный в исследовании Е.Ю.Стратийчук показал, что общими лексико-семантическими средствами выражения текстовой категории персональности в русском и английском языках являются эпитеты, ассоциативно-образные сравнения, эмоционально-экспрессивная лексика, антропоморфизмы, коннотативные значения слов [8].

Грамматическими же средствами выражения категории персональности являются авторизирующие глаголы, обращения к читателю, парцеллированные конструкции и риторические вопросы, сочинительные союзы, безличные предложения, вводные слова и выражения, модальные глаголы, а также предложения, подлежащее которых выражено 
местоимением 1 лица единственного числа. Все вышеперечисленное позволяет определить говорящего, участника речи, а также того, кто в речи не участвует [9].

Персональная сетка - это совокупность средств морфологического, синтаксического и словообразовательного уровня, обеспечивающих ориентацию читателя в личностном аспекте текста, где во внимание принимаются все языковые средства данного текста, обладающие признаком «наличие лица» или содержащие ссылку на лицо. Это могут быть эксплицитные (личные местоимения, личные формы глагола, притяжательные местоимения, обращения, императив) и имплицитные (модальные глаголы, междометья, частицы, вопросительные предложения) средства, а также единицы, в семантике которых есть указание на лицо [10, 60-64].

Эксплицитная сетка в зависимости от преобладающих в ней языковых средств выражения лица подразделяется на следующие подтипы: прономинальная, глагольная, императивная. Имплицитная сетка представлена адвербиальным, конъюнктивным и интеррогативным подтипами.

Цель данной статьи - определить, какие типы персональных сеток встречаются в описаниях дематериализации субъекта и какую роль они играют в ее языковой реализации.

\section{Материалы и методы}

Материалом для исследования послужили произведения Артура Чарльза Кларка (Город и звезды, Лунная пыль), Рэя Дугласа Брэдбери (Кладбище для безумцев), Стивена Кинга (Под Куполом, Туман), Ричарда Дэвида Баха (Мост через вечность) и Колина Уилсона (Паразиты сознания).

Цель исследования достигается методом контекстуального, компонентного и стилистического анализа и методом классификации, позволяющим систематизировать результаты проведенного анализа.

\section{Обсуждение}

Прежде чем перейти к рассмотрению средств выражения категории персональности в описаниях дематериализации субъекта, отметим, что в ходе анализа мы опирались на трактовки понятий «дематериялизация» и «персональная сетка», приведенные во Введении.

Как правило, дематериализация представляет собой длительный или мгновенный процесс. Рассмотрение любого процесса предусматривает изучение семантического субъекта глагола, который, согласно В.И.Карасику, «...может быть одушевленным, неодушевленным и недифференцированным. Одушевленный субъект выражается как лицо (thank благодарить) либо живое существо (calve - отелиться). Неодушевленный субъект выражается как вещество, предмет, явление, событие (vaporize - испаряться, consist состоять из чего-либо). Недифференцированный субъект может быть предельно широким (be - быть, become - становиться) либо потенционно-персональным (break - разбивать, change - меняться)» [11]. Обратимся к примерам:

1.Fortunately, before Hilvar could press the inquiry any further, the polyp emerged once more from the lake. In the last few minutes it had become a good deal smaller and its movements were more disorganized. Even as Alvin watched, a segment of its complex, translucent body broke away from the main bulk and then disintegrated into multitudes of smaller sections, which swiftly dispersed. The creature was beginning to break up before their eyes.

(The City and the Stars, Arthur Clarke)

2.When it is time for the Going Away, Christ touches each of his disciples and then walks up along the shore, away from the camera. Set your camera low in the sand, and it looks as if he were climbing a long slow hill. And as the sun rises, and Christ moves off toward the horizon, the sand burns with illusion. Like highways or deserts, where the air dissolves in mirages, imaginary cities rise and fall. Well, when Christ has almost reached the top of a dune of sand, the air vibrates with heat. His shape melts into the atoms. And Christ has gone.

(A graveyard for lunatics, Ray Bradbury)

3. At regular intervals, a cylindrical grab was disappearing into the well, to be hauled back to the surface a few seconds later by a small but powerful crane. On each withdrawal, the grab would be swung clear of the opening, and would disgorge its contents back into the Sea. For an instant a 
gray dunce's cap of dust would stand in momentary balance on the level plain; then it collapsed in slow motion, vanishing completely before the next load had emerged from the shaft.

(A Fall of Moondust, Arthur Charles Clarke)

B данных примерах категория персональности выражается эксплицитными средствами. В примере 1 - через недифференцированный-потенционно-персональный семантический субъект глагола: местоимение it и предикат had become сообщают о недифференцированности субъекта, тогда как глаголы broke away, disintegrated, dispersed, was beginning, break up) наделяют его персональными качествами.

Персональная сетка второго примера представлена флексией глагола (третье лицо единственного числа настоящего времени общего вида - melts и has gone) и притяжательным местоимением 3-го лица ед.ч. (his shape melts into the atoms). Несмотря на то, что melt (таять) является глаголом неодушевленного предмета, в сочетании с притяжательным местоимением his, он обозначает действие живого существа (Christ).

В третьем примере категория персональности формируется местоимением it, предикатами в форме Past Simple (collapsed, went transparent) и деепричастием vanishing, выражающими дифференцированный неодушевленный предмет (grab). Глагол collapse в сочетании с прилагательным slow замедляет процесс исчезновения.

Выделенные средства сигнализируют о длительном характере изображаемого явления. Процесс дематериализации растянут во времени и осуществляется поэтапно. В первом и третьем примерах на это указывает личная форма глагола begin, деепричастие vanishing и прилагательное slow, во втором - процессуальный глагол melt.

4. The survivors at the Dome watched silently as the van tore down the dirt track that led back to what Norrie Calvert had taken to calling "the flash-box." The Odyssey dimmed into the hanging smog, became a phantom, and then disappeared.

(Under the Dome, Stephen King).

5 . The spider gave up. It could not smell us, ergo we were no longer there. It strutted back into the mist on its unsettling number of legs, became a phantasm, and then was gone.

(The Mist, Stephen King)

6. The kid, had known! The kid I was had stood at this gate and known that the woman that he was born to love would one day be here...The boy went transparent and vanished, eyes goggling wonder, mouth still open, and the moment was gone.

(The Bridge Across Forever, Richard David Bach)

B приведенных контекстах персональность представлена недифференцированным (became a phantom, was gone, vanished) и неодушевленным (dimmed, disappeared, went transparent) субъектами глагола. Персональные сетки здесь, как и в предыдущих примерах, носят эксплицитный характер. Однако, в отличие от уже рассмотренных средств, выделенные предикаты никак не способствуют замедлению изображаемого процесса, т.к. все до одного являются событийными (в форме Past Simple), т.е. обозначают динамику действия. Вкупе они сообщают о том, что исчезновение происходит почти что мгновенно.

7. I was trying to move my head on the pillow, change position, when I realized that I couldn't do that because the pillow was down on the bed and I was floating on my back, three feet in the air.

Wide awake. Floating. The room was wall-to-wall in dark silver-grey ight. Moonlight, I would have said, but there was no moon. There the walls, the stereo cabinet; there the bed, books neatly on her side, a tumbled stack on mine. And there our bodies, asleep!

A jolt of pure astonishment, like blue fire through me in the night, and then an explosion of joy. That was my body, down there; that curious thing on the bed was me, eyes closed, sound asleep! Not quite me, of course ... me was the one who was looking down.

(The bridge across forever, Richard Bach)

8. It was now that my remote contact with Holcroft told me that he was still descending. I was filled with admiration. I had become absolutely weightless at that depth. My consciousness was like a bubble that wanted to rise. I knew there was some "knack" of getting deeper, but acquiring a knack takes a certain amount of exploration, of practice, and if it is all you can do to remain conscious, this is impossible. Holcroft obviously had the knack already.

(The Mind Parasites, Colin Wilson)

В этих отрывках категория персональности представлена эксплицитно, личными местоимениями I, me, притяжательным местоимением my, фразой had sense и глаголами 
realized, knew, т.е. через одушевленный субъект. Дематериализация субъекта происходит в процессе погружения рассказчика-наблюдателя в собственное сознание. Субъект переживает внетелесный опыт - покидает собственное тело. Дематериализация, однако, не приводит к его обезличиванию. Он, хоть и неясно, по-прежнему ощущает себя (I didn't exactly have a body, but neither was I without one. I had a sense of body-hazy, foggy, a ghost's body; weightless, like a bubble), собственное сознание (I, had sense, realized, my consciousness, I knew) и сохраняет способность испытывать эмоции (astonishment, joy, admiration).

\section{Выводы}

Анализ текстов, содержащих описания дематериализации субъекта, показал, что последняя моделируется эксплицитными персональными сетками. Дематериализация субъекта осуществляется за счет использования личных форм глагола (Past Simple, Past Continuous), изображающих это явление либо замедленным, растянутым во времени, либо ускоренным, почти что мгновенным. При этом скорость исчезновения напрямую зависит от типа глагола - процессуальные предикаты способствуют замедлению дематериализации, тогда как событийные предикаты, напротив, ускоряют ее. Иными словами, использование тех или иных предикатов в описаниях дематериализации субъекта обусловлено стремлением автора задать определенный темп описываемому процессу - замедленный или мгновенный.

Помимо предикатов в описаниях дематериализации субъекта участвует эксплицитная персональная сетка прономинального типа, представленная местоимениями 1 л. ед.ч. (I, те, my) и 3 л. ед.ч. (it, his). При этом местоимение I указывает на наличие сознания у дематериализованного субъекта, а местоимение it сообщает о его недифференцированности. С помощью данных средств автор фокусирует внимание читателя на психологическом состоянии дематериализуемого, его ощущениях и эмоциях.

\section{Примечания:}

1. Дематериализация (материал из Википедии) // http://ru.wikipedia.org

2. Психиатрия: Учебник для студ. мед. вузов / М.В. Коркина, Н.Д. Лакосина, А.Е. Личко, И.И. Сергеев. 3-е изд. М.: МЕДпресс-информ, 2006. 576 с.

3. Что такое телепортация? // Х-архив сакральных знаний // http://omkling.com/?p=977

4. Телепортация: прыжок в невозможное / Дэвид Дарлинг. Москва: Эксмо, 2008. 300 с.

5. Телепортация - что это такое? // Здоровье - энергия пирамид // http://luksmed.ru /page8.html

6. Дематериализация // Уфологический словарь-справочник // http://ufodic. org.ua/dematerializaciya

7. Ноздрина Л.А. Поэтика грамматических категорий. Курс лекций по интерпретации художественного текста. М.: Диалог-МГУ, 2000. 232 с.

8. Стратийчук Е.Ю. Персональность как текстообразующая категория художественного текста (на материале русского и английского языков): автореф. дис. канд. филол. наук. Ростовн/Д., 2006. 12 с.

9. Слюсарева Н.А. Проблемы функционального синтаксиса современного английского языка. М.: Нука, 1986. 214 с.

10. Ноздрина Л.А. Грамматика и поэтика // Филологические науки. 1993. № 5-6. С. 59-69.

11. Карасик В.И. Язык социального статуса. М.: ин-т языкознания РАН; Волгогр. гос. пед. ин-т, 1992. 330 с.

\section{References:}

1. Dematerializatsiya (material iz Vikipedii) // http://ru.wikipedia.org

2. Psikhiatriya: Uchebnik dlya stud. med.vuzov / M.V. Korkina, N.D. Lakosina, A.E. Lichko, I.I. Sergeev. 3-e izd. M.: MEDpress-inform, 2006. 576 s.

3. Chto takoe teleportatsiya? // X-arkhiv sakral'nykh znanii // http://omkling.com/?p=977

4. Teleportatsiya: pryzhok v nevozmozhnoe / Devid Darling. Moskva: Eksmo, 2008. 300 s.

5. Teleportatsiya - chto eto takoe? // Zdorov'e - energiya piramid // http://luksmed.ru/page8.html 
6. Dematerializatsiya // Ufologicheskii slovar'-spravochnik // http://ufodic.org.ua /dematerializaciya

7. Nozdrina L.A. Poetika grammaticheskikh kategorii. Kurs lektsii po interpretatsii khudozhestvennogo teksta. M.: Dialog-MGU, 2000. 232 s.

8. Stratiichuk E.Yu. Personal'nost' kak tekstoobrazuyushchaya kategoriya khudozhestvennogo teksta (na materiale russkogo i angliiskogo yazykov): avtoref. dis. kand. filol. nauk. - Rostovn/D., 2006. 12 s.

9. Slyusareva N.A. Problemy funktsional'nogo sintaksisa sovremennogo angliiskogo yazyka. M.: Nuka, 1986. 214 s.

10. Nozdrina L.A. Grammatika i poetika // Filologicheskie nauki. 1993. № 5-6. S. 59-69.

11. Karasik V.I. Yazyk sotsial'nogo statusa. M.: in-t yazykoznaniya RAN; Volgogr. gos. ped. in-t, 1992. $330 \mathrm{~s}$.

УДК 81’23:811.111

Типы персональных сеток в текстах, содержащих описания дематериализации субъекта

\author{
1 Элла Владимировна Нестерик \\ ${ }^{2}$ Наталья Сергеевна Рожаева
}

\begin{abstract}
${ }^{1}$ Карагандинский государственный университет им. Е.А.Букетова, Казахстан 100026, Карагандинская область, г. Караганда, ул. Муканова 1а

Кандидат филологических наук, доцент

E-mail: ella_nesterik@mail.ru

${ }^{2}$ Карагандинский государственный университет им. Е.А.Букетова, Казахстан 100026, Карагандинская область, г. Караганда, ул. Муканова 1а E-mail: minik25@mail.ru
\end{abstract}

Аннотация. В статье исследуются типы персональных сеток, встречающихся в описаниях дематериализации субъекта, выявляется роль средств выражения категории персональности в языковом воплощении данного феномена. Исследование проводится на стыке нескольких дисциплин, среди которых ведущее место занимает лингвистика текста. Авторы приходят к выводу, что дематериализация формируется в художественном тексте эксплицитными средствами выражения персональности - предикатами определенного типа и прономинальной персональной сеткой.

Ключевые слова: дематериализация; категория персональности; персональная сетка; эксплицитные средства выражения персональности; эксплицитная персональная сетка; языковое воплощение дематериализации. 